\title{
Digital Inbound Marketing to Drive the Success of Startups
}

\author{
Chitral P. Patel ${ }^{1 *}$, Pawan Kumar Chugan ${ }^{2}$ \\ ${ }^{1}$ Research Scholar, Kadi Sarva Vishwavidhyalaya, Gandhinagar, Gujarat. India \\ ${ }^{2}$ Professor, Institute of Management, Nirma University, Ahmedabad, Gujarat. India
}

Received: December 26, 2017; Accepted: January 29, 2018; Published: February 08, 2018

*Corresponding author: Dr. Chitral P. Patel, Research Scholar, Kadi Sarva Vishwavidhyalaya, Gandhinagar, Gujarat, India. Email:-patelchitral@gmail. com

\begin{abstract}
The present'Startup-India' ecosystem is very encouraging and has been attracting many entrepreneurs to start a new business and incubators have been playing a crucial role in expanding Indian economy. However, not all startups succeed because of the various risks such as cash burn, poor product, poor marketing, founders' vision, product pricing, legal challenges, etc. Amongst these, the communication with the prospective customers for the new products or services play crucial role and success of the startups highly depends upon not only the messages to customers but also on the ways and cost of communication viz. cost advertising, marketing and promotions. It is, therefore, highly desirable for startups to convey their messages to the right customers with proper marketing tools and actions with the least possible cost. Traditional marketing methods cost a lot more and in the initial stages in particular, may prove to be a major constraint for the success of startups. Therefore, it is important to design inbound marketing activities to help drive growth, in the generated or targeted leads with minimal or no cost. Instead of broadcasting to the customer, inbound marketing focuses on creating reasons for the customer to come to seller by using compelling content and appearing in search engine results. Therefore, an attempt has been made in this paper explores the key trends, opportunities and strategies in inbound approach for the startups over the coming year - covering topics such as customer experience, content optimisation, data-driven marketing, etc. for the success of startups.
\end{abstract}

Keywords: Inbound Marketing; Startups; Digital Marketing; Content Marketing

\section{Introduction}

\section{Growth of start-ups}

A report by NASSCOM stated that, "India has emerged as the third largest start-up base and such ventures are poised to grow 2.2 times to reach 10,500 by 2020 [12].The start up landscape in the country is becoming the epitome of innovation, with companies bringing out solutions that are aimed at solving locally relevant issues". The report also claimed that, "the contribution by startups have been growing at a rapid rate and the landscape has a huge potential in terms of business stability, revenue growth and further innovation".
Investors are more interested in Fintech, Healthtech, Edutech, data analytics, B2B commerce and artificial intelligence. One of India's most celebrated entrepreneurial minds, NR Narayana Murthy, stated that, "I wouldn't think there is anything lacking among Indian start up entrepreneurs. What is missing is the readiness of Indian corporations and markets to absorb new ideas and technologies to derive competitive advantage for growing faster and profitably" [7].

Indian startups saw $\$ 3.5$ billion invested across over 815 deals between Q1-Q3, 2016 [2]. Not all startups succeed due to many reasons. According to Lance, $29 \%$ of startups fail because they run out of cash may be due to underfunding to spending recklessly and $14 \%$ fails due to poor marketing of their product [Figure 1] [10]. Some founders by thinking that the product will advertise for itself, they market it to the wrong audience or via wrong channels.

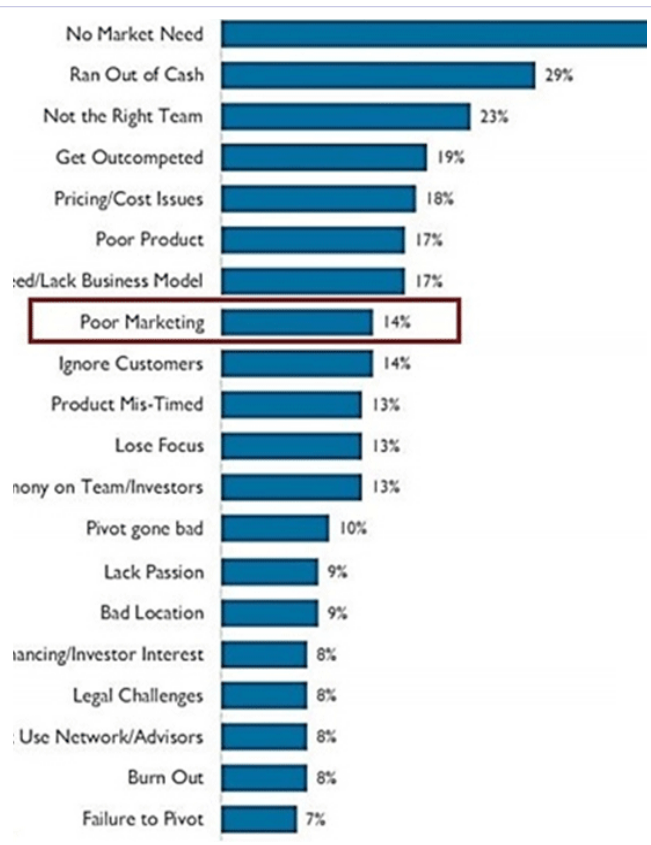

Figure 1:Top 20 Reasons for Startups Failure 


\section{Digital Marketing and Inbound Marketing}

According to Skinner, "Digital Marketing can hold great potential for those wanting to increase exposure, sales or leads [15]. But with so many different channels, platforms, techniques, media formats and service providers in the industry, it can be over whelming". In a survey of 55 startups, Skinner concluded the following:

- Startups are clearly keen to invest time and budget in digital marketing in order to deliver results.

- There is a surprising lack of any documented strategy / planning.

- The very high use of analytics by startups shows there's a real desire to measure and make their marketing work. With Earned media, high on the agenda for half of all startups, how can tools measure its success?

- The lack of investment in Paid media suggest startups don't have the capital to do it properly or don't think it will bring in a return. Perhaps advertisers need to alter their business model to deliver viable options for startups.

- Social Media and Content Marketing were voted top tactics, despite most startups wanting new customer acquisitions over brand awareness. Social Media in particular isn't regarded as a great lead generation channel. Does this suggest startups are unfamiliar with the channel or choosing channels based on budget?

- With so few (8\%) startups investing in an agency or consultant, should these suppliers alter their cost models to cater for startups? Perhaps more startups should be able to pay via stock, skills, service or products?

- Startups are doing a great deal of marketing elements themselves without any formal training. This represents a potential opportunity for agencies/consultants to help with Content Marketing and Online PR in particular.

- An overarching question is how to make the above work commercially when startups are typically light on budget?
Inbound marketing is a type of digital marketing strategy which utilizes pull marketing in today's online world. This online pull marketing includes social media marketing, blogs, Search Engine Optimization (SEO), content marketing, etc. Using inbound marketing, companies big or small, can create brand awareness and hence attract new business. As per HubSpot, "Inbound marketing is said to be the best way to turn strangers into paying customers and promoters of your business" [9]. According to Blake, generally, inbound marketing and digital marketing are unique in two distinct ways: Firstly, "Inbound marketing is an entire marketing methodology, while digital marketing is a broader term for elements used to digitally connect with consumers (often in the form of visual overhauls, graphics or logos)[4]. And secondly, inbound marketing consists of countless moving, interrelated parts, (blogging, content offers and conversion elements, to name a few), which take a steady balance of time and expertise to implement correctly; digital marketing, on the other hand, is the practice of marketing to users across digital platforms with elements like banners, brand recognition and advertisements".

Inbound marketing is different from outbound marketing in terms of gaining customers. While in outbound marketing, marketers attempt to find customers with traditional marketing techniques, in inbound marketing, marketers earn the attention of potential customers and through unique content, makes the brand easy to be found.

According to Woodard, "Inbound marketers focus on creating quality content that is of interest to potential customers and pull them toward the company and product [21]. Inbound marketing doesn't force customers or convince to buy impulsively, but rather nurtures them at every stage of the conversion funnel and makes them buy naturally when they want to. Inbound marketers align the content with customer's interests and naturally attract the visitors which can be converted, closed and delighted over time" [Figure 2].

In nutshell, inbound marketing is a technique of producing and sharing quality content, rather than making efforts to

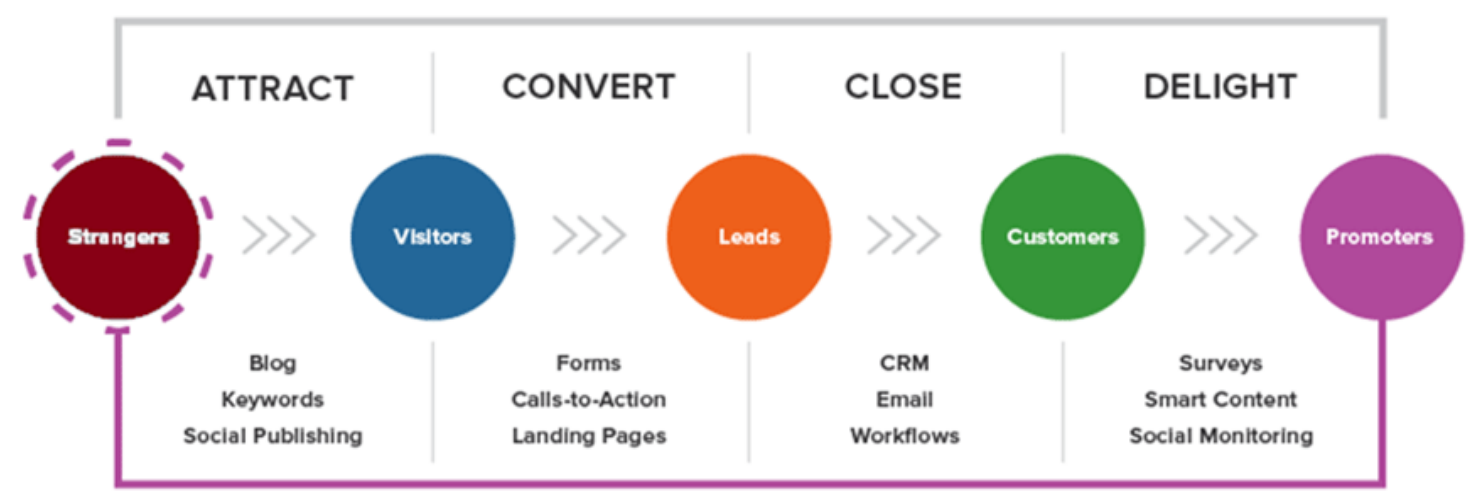

Source: Woodard (2016)

Figure 2: How Inbound Marketing Works 
fight for customer's attention. While explaining the difference between inbound and outbound marketing, Gregg stated that, " $45 \%$ of direct mail never gets opened, 200 million people were on the national 'Do Not Call Registry' and $85 \%$ of people fast forward through commercials" [8]. He also claimed that, "84\% of 25-35-year-olds were likely to click off a website with excessive advertising".

\section{Literature Review}

\section{How inbound is disrupting today's business}

As per a global survey of 7,000 marketing professionals, "customer experience remains a top priority and is now defining other priorities" [1]. According to the report, "personalisation and content optimisation are the highest priority digital-related areas and mobile remains a top- 3 priority for more than half of the respondents".

Chaffey has pointed out how importance of mobile marketing and apps has been growing since past few years [6]. His article highlights important statistics for the key digital trends and claimed that, "more than $50 \%$ of searches were on mobile and 91\% of Facebook usage (Daily Active users) was on mobile. $80 \%$ of Facebook advertising revenue was on mobile and $90 \%$ of mobile media time was spent in apps".

Moreover, the report also points out content and inbound marketing as a 'mega-trend for 2016-17'. Over the past three or four years, readers have voted for the importance of Content Marketing amongst the marketing activities available as an activity businesses are focusing on to achieve growth. It is highly necessary to get the right balance of content quantity, frequency and quality and of course, measuring the Return-on-Investment of Content Marketing.

According to Stelzner, "marketers plan to increase their use of videos (73\%), visuals (71\%), blogging (66\%), live video (39\%), and podcasting (26\%), in the near future" [17]. As marketers plan their 2017 strategies, it's become apparent that online visibility is a key component for almost everyone [3]. In fact, a recent study by HubSpot of more than 4,500 professionals found that SEO and content creation lead the list of top priorities [9] (Figure 3).

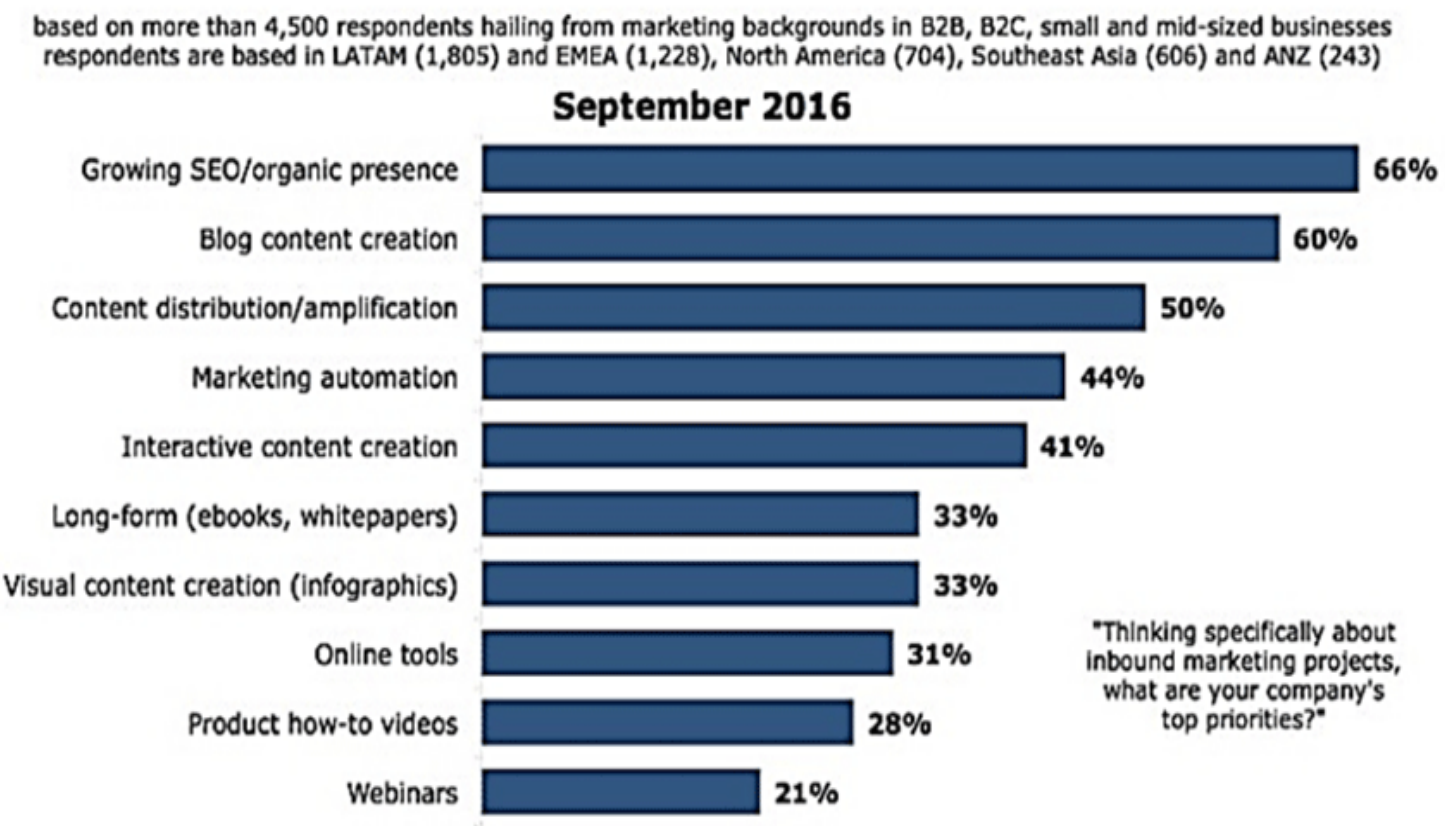

Figure 3: Top Inbound Marketing Priorities

The most exhilarating experience is starting one's own venture. Some of the big questions that follow are how to reach masses, how to make one's business resonate, how to drive business results, how to be successful, and how to fulfil dreams with a shoestring budget? Startups solve specific problems for their users and hence getting the message spread to the right users is very important [22]. Also, being a start up, they cannot spend as much as big businesses do and a slow growth in this fast-paced competitive world is also detrimental to start ups' existence.
We are living in a world which is just making transition from information age to experience age [20]. All businesses, big or small, needs to do marketing. According to Patel, "most of the conventional marketing approaches are too expensive or unwieldy for smaller businesses and startups to successfully employ" [13]. Hence, inbound marketing makes sense for all businesses, especially for small businesses and startups. "Millennials, the fastest growing consumer base are very likely to do an online search of businesses they plan on buying from; if you're not there, you are missing out"[19]. 
Marketers all over the world have witnessed unprecedented changes in marketing from customer engagement to data measurement. Furthermore, buyers today are also more empowered with the web providing them with instant information gratification. Customers have access to detailed product specifications, pricing, and reviews $24 / 7$ with just few clicks. The growth of social media has also encouraged them to share their experiences, good or bad, particularly mobile devices adding a 'whenever/wherever' dimension to their sharing experience. It is necessary for the companies to provide with content which can hold them on, keep them captivated and at the end leave them always wanting for more [13].

In this scenario, inbound marketing serves as a boon for upcoming brands or startups to provide the searcher or customer the answers they seek and precisely when they need it. This approach helps in building trust and reputation especially when the start up is serving a niche.

Inbound marketing approach offers many techniques where there are organic ways to grow the customer base without pouring in large sum of money. Also, there are low entry barriers in using the techniques. For a start up, inbound marketing helps in building awareness and brand positioning. Inbound marketing builds a consistent traffic flow which drive leads and online sales.

According to Tom, "inbound marketing approach provide value to the customers' life, engage with them on a personal level that better helps their buying process" [19]. Stamoulis stated in an article that, "it's not about trying to create a want or a need; it's about satisfying a want or a need that already exists. In other words, people find your content online and when they feel compelled, they join in on the conversation" [16].Inbound marketing constitutes of mainly Content Marketing, Pay-Per-Click (PPC), Search Engine Optimization (SEO), and Social Media. The detailed discussion of these methods is beyond the scope of this paper; however, steps or strategies that may be taken are given the following pares.

\section{Objectives of the Study}

- To study the trends of digital and inbound marketing

- To analyse and discuss inbound marketing strategies for startups which help them to get more business for sustainable growth

\section{Research Methodology}

The exploratory research design is used for analysing and studying the digital inbound marketing strategies for business growth. Secondary data for the study were collected from magazines, websites and previous studies.

\section{Digital Inbound Marketing Strategies For Startups}

Many startups have a tough time in fully understanding the nuances and the time needed to execute effective inbound marketing methods and campaigns. Based on the available literature, the following are the inbound marketing strategies that startups may like to adopt for success and sustainable growth of their business.
Inbound marketing is a marketing activity that brings visitors in, rather than marketers going out to get prospects' attention. The process of Inbound Marketing involves gaining the attention of prospects or customers, helps the company get noticed online easily on search engine pages, and draws customers to their website by providing interesting content.

Any inbound marketing strategist would justify that fast adoption of social media and content marketing about product, events and activities is indeed a first and important step to get attention of the prospective customers. However, many startups are still failing to make the most out of their inbound marketing activities. They do provide a great content, but somehow, they aren't able to capitalize on it by channelling prospects towards a sale.

Here are few strategies that startups may bank upon for successful lead conversion into sales using inbound marketing for their business growth:

\section{Plan an Inbound Marketing Campaign}

A proper strategy is the building block of the whole campaign. Without proper planning, all other efforts will go in vain costing time, energy, money and of course customers.

With proper strategic planning, a start up company will succeed in acquiring new leads and can nurture them accordingly and hence establish a rapport and with their brand.

\section{Identify Prospects}

Before a start up jumps into target marketing, it is of utmost importance that first it needs to identify the target audience. Depending upon the audience, a start up needs to create and customize its campaigns accordingly so that its message gets delivered at the right place and to the right persons.

\section{Mark Online Presence}

Buyers these days are provided with almost every piece of information regarding the product or service they are interested in before making the purchase. Now, they first search for the company's website and seek all information they want and then may or may not make a decision to purchase from their website.

Having an active and responsive website should be at priority. The organization which has a website with all relevant details available seems to be credible to customers. This helps in building brand awareness and providing information which prospects are looking for, sharing the start ups' website URL to others if not relevant to them.

\section{Accessible and Useful Content}

The website should contain all content related to the products and services that the start up is offering. This may include howto guides, do-it-yourself videos or imagery, blogs on features information, latest product updates, industry news, etc.

Apart from these regular details, the website should have some original, creative and engaging content so that prospects spend maximum time on the start ups' website, giving them 
reason to visit website frequently and finally ends up with the decision to buy company's products.

The website and blogs should be accompanied with proper tags and categories for optimized search.

\section{CTA (Call-to-action) Button}

Digital marketers have found out from A/B testing of websites that the chances of lead conversion increases when the content is paired with a call-to-action button. If a company wish that when a prospect reads a content on its website and it prompts the visitor to download the brochure or contact form, etc., there should always be a 'download now', 'click here to know more' etc. button where they opt-in to get updates by providing their email id or contact number.

Many features like virtual tour and chats are available but provide little or no opportunity for action.

\section{Continuous Tracking and Reporting}

With many paid and free website tracking tools, tracking the website activity is vital for analysing performance and taking necessary actions in case the website shows poor engagement activity. Tracking and analysing data also helps in calculating the ROI goals set during the strategy phase.

Due to increase in number of the startups every year with more or less similar products sometimes, creating a highly competitive environment, it is important to provide a customized, targeted, creative and engaging content which compel prospects to make a purchase.
The startups that understand 'Inbound Marketing' and its tactics, will perform more effectively in attracting prospective customers for their products or services.

\section{Be Frequent and Consistent}

Inbound marketing can play an important role in communicating the brand's voice. Marketers, apart from creating and posting content regularly, should also maintain a uniformed identity to the content. However, over posting is harmful and the content should not deviate from brand's message.

\section{Engage with the Followers}

According to Miller, "Social media is a way for a start up to interact with current and future customers [11]. Leverage the followers and make them feel like valuable members of your brand".

Due to ease of access to social media, customers share their complaints, reviews or issues openly via company's Facebook page, Twitter account or other review sites. A Start up should proceed with any complaint or issue as an opportunity to show its capabilities towards customer-service. A start up,being new in the market, often to faces obstacles along the way. The company should strategically look forward such issue as an opportunity to win over the potential or current customers with excellent customer service and communicate brand's vision repeatedly.

\section{Mobile optimization strategy is no longer an option}

As may be observed from the figure 4, mobile search has surpassed desktop being the most recent major change in the

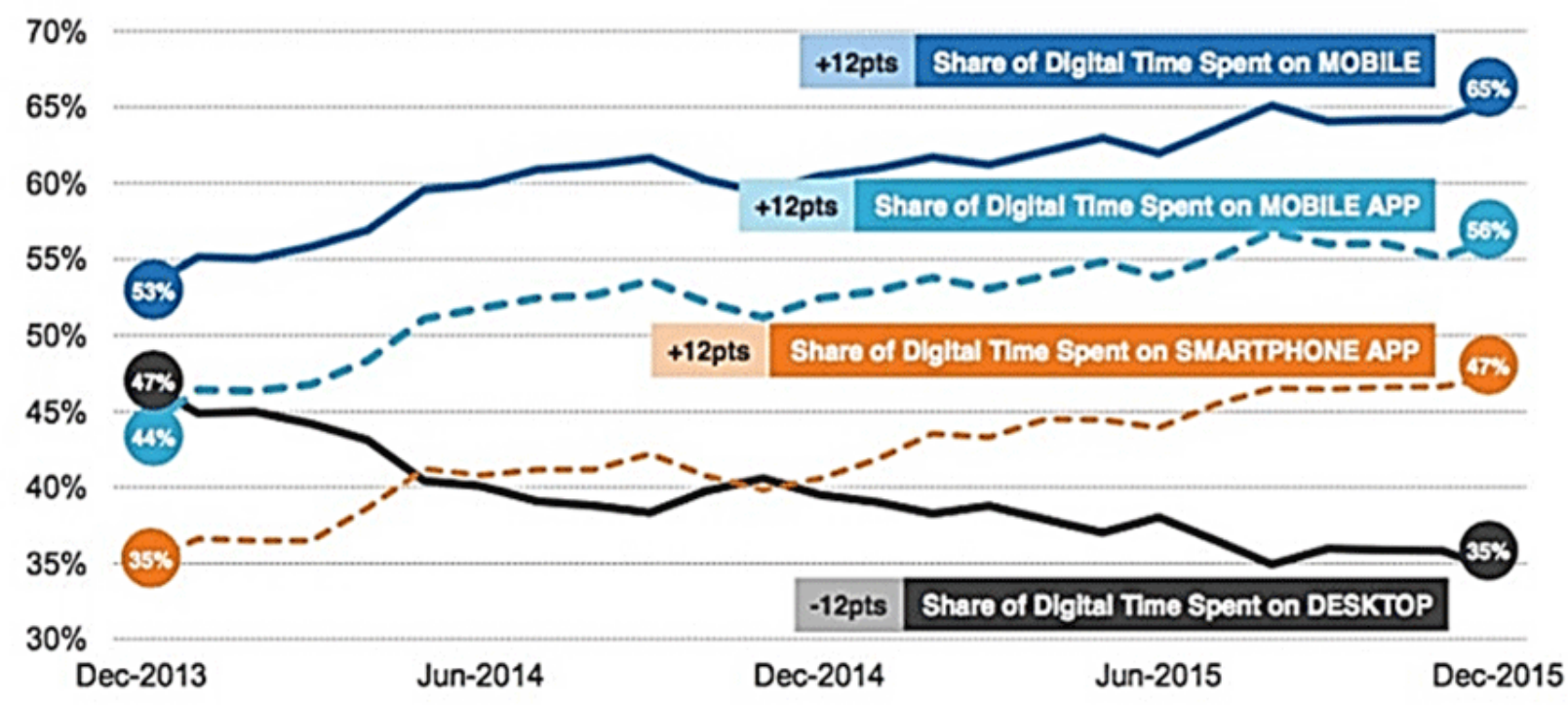

Source: www.marketingland.com

Figure 4: Share of Digital Media Time Spent by Platform 
digital landscape. This, according to Sterling, "makes clear that mobile is now the growth driver, while the desktop is rapidly becoming a secondary touch point"[18].

Google has updated its algorithm compelling all online marketers to design the websites in a mobile friendly format. As per Broadbent, if a website is not designed in a mobile friendly format, the company's business "could suffer the consequences of users being dissatisfied and bouncing back to search results [5]. Google has included mobile as one of their ranking signals [Figure 4].

\section{Implement Conversion Rate Optimization (CRO) Techniques}

Every start up company's website should have some point of interaction for a visitor, whether it is subscribing to newsletter or blog, filling out a contact form or purchasing product, service or subscription. Conversion Rate Optimization (CRO) is the art and science of improving the chances to engage the passive website visitors into active audience interacting on the website and finally complete more goals.

Marketer need to analyse and determine how to best optimize a website, implement A/B split testing and then make the necessary adjustments to Call-To-Action (CTA) buttons, web copy and sign up forms etc. This becomes even more crucial when the startups have an e Commerce business, with cart abandonment rates at an average of $68 \%$, therefore it is necessary to optimize the shop and cart pages for conversions [5].

\section{Conclusion}

In today's fast-paced market, the Internet and social networking are influencing daily decisions of consumers. Due to open source nature of the internet and billions of users joining the network daily, customers are now exposed to more information than ever before. The information shared over the Internet is not only making the audience educated and aware, but also influencing their purchase behaviours. As a result, the startups' marketing efforts must be fine-tuned in a way to respond to this paradigm shift.

Today's small businesses and startups are realizing that outbound efforts alone are not enough to produce profits. Hence, inbound marketing techniques are required to be used in order to attract more leads and foster better brand preference. This is even more relevant and important for startups because typically they are light on their budgets and have many financial constraints. To be successful in inbound marketing, startups as also other businesses need to introduce a disciplined approach to content creation, add marketing automation tools that can help them nurture and score leads, and optimize how these leads flow through the sales pipeline for the success and sustainable growth of business.

NOTE: This paper is revised and updated paper of the draft (unpublished) paper titled as "Inbound marketing: strategies for start-ups for success and sustainable growth" which was presented in the NICOM 2017, during January 2017. The suggestions received from the participants have been included in this revised paper.

\section{References}

1. Adobe. Digital Trends for 2016. 2016.

2. Amberber E. $\$ 3.5$ bn Poured into 815 Deals In 9 Months - An Average Of \$13 mn Invested Per Day in Indian startups. 2016.

3. Barqar. Top Inbound Marketing Priorities in 2017.2016.

4. Blake I. What's the Difference Between Inbound and Digital Marketing?. 2015.

5. Broadbent A. 5 Tips Entrepreneurs Need to Know About Digital Marketing. 2015

6. Chaffey D. Digital Marketing Trends 2016-2017. 2016.

7. Forbes. Nothing Lacking in Indian Start up Entrepreneurs, Says Narayana Murthy. 2016

8. Gregg Z. Inbound Vs. Outbound: Why Is Inbound Marketing Better Than Outbound Marketing?. 2014

9. HubSpot. The Ultimate List of Marketing Statistics. 2016.

10. Lance V. 20 Reasons Why Startups Fail [Infographic]. 2016

11. Miller D. 8 Digital-Marketing Tips for Bootstrapped Startups. 2015.

12. NASSCOM. India Will Be Home To 10,500 Startups By 2020: Nasscom, The Economic Times. 2016

13. Patel C. Inbound Marketing for College Universities. 2015.

14. Patel N. 6 Inbound Marketing Techniques Every Business Should Use. 2016.

15. Skinner C. I Asked 55 Startups About Their Digital Marketing. Here's What I Found. 2015

16. Stamoulis N. 4 Types of Inbound Marketing. 2016.

17. Stelzner M. 2016 Social Media Marketing Industry Report. 2016.

18. Sterling G. All Digital Growth Now Coming from Mobile Usage comScore. 2016.

19. Tom. You Need an Inbound Marketing Strategy In 2017. 2016.

20. Wadhera M. The Information Age Is Over; Welcome to the Experience Age. 2016

21. Woodard R. Why Macklemore Is the Inbound Marketing Master. 2016.

22. Your story. Digital Marketing for Startups. 2016. 